\title{
Availability of Cadaveric Kidneys for Transplantation
}

\author{
DAVID L. CROSBY, ROBERT R. WEST, HELEN DAVIES
}

British Medical fournal, 1971, 4, 401-402

\section{Summary}

The availability of cadaveric donor kidneys for transplantation has been estimated from a retrospective survey of hospital deaths in Wales during 1969. Seventysix "probable donors" and 167 "possible donors" were identified, indicating that the potential supply of donor kidneys is sufficient to meet the present demands of patients needing kidney transplantation.

\section{Introduction}

Both cadaveric kidney transplantation and maintenance haemodialysis are palliative forms of treatment, and the continuing referral of new patients with terminal renal failure leads to cumulative demands on the facilities of regional haemodialysis units (British Medical fournal, 1971b). The 12 kidney transplant units in England and Wales supported by the Department of Health and Social Security have the capacity to undertake the treatment of more patients (British Medical fournal, 1971a), but have been prevented from doing so by a persistent shortage of cadaveric donor kidneys. If this situation is to be improved it is important to know whether it is due to an actual shortage of suitable cadaveric donors or to failure to use donors that are potentially available. We report here the results of a survey designed to clarify this point by estimating the number of donor kidneys which might have been obtained from hospital deaths in Wales during 1969.

\section{Methods}

Potential kidney donors were selected from patients who had died in 27 general hospitals in Wales during 1969, by retrospective study of their clinical records. The primary source of information was the data collected for Hospital Activity Analysis (H.A.A.). This is a management information system whereby administrative details and brief clinical summaries of hospital inpatients are coded and stored on magnetic tape at the Welsh Hospital Board's Computer Centre. Computer analysis of the H.A.A. data available for 1969 identified 325 patients aged 15 to 55 years who had died in hospital and whose coded diagnoses did not include malignant disease (other than primary brain tumours), hypertension, urinary tract disease, or transmissible infections. The computer listed a further 249 patients who satisfied the age requirements but whose H.A.A. records were otherwise incomplete. One of the two neurosurgical units in Wales was not included in the H.A.A. system in 1969, and the clinical records of 28 patients aged 15 to 55 years who died in this unit were obtained independently. Finally, the records of eight patients who had died in emergency admission units before they had been registered as inpatients were included

Kidney Transplant Unit, Cardiff Royal Infirmary, Cardiff CF2 1SZ

DAVID L. CROSBY, F.R.C.S., Consultant Surgeon

HELEN DAVIES, M.B., B.CH., House Surgeon

Department of Statistics, University College, Cardiff CF1 1XL

ROBERT R. WEST, M.A., PH.D., Research Fellow in the study. A total of 610 hospital deaths were thus selected and the clinical records of 581 of these were studied in detail. The remaining 29 had to be excluded because their clinical records could not be traced or were incomplete.

Patients whose clinical records revealed a terminal period of oliguria and hypotension exceeding 12 hours were excluded as potential donors (urine output $<100 \mathrm{ml}$; systolic blood pressure $<90 \mathrm{~mm} / \mathrm{Hg}$ ). Also excluded were those patients who were found to be dead on arrival at hospital or who died within one hour of admission. The remaining patients were listed as potential kidney donors on the evidence of the clinical information which had been available at the time of death. Necropsy findings were noted but were not used to decide whether a particular patient might have been a suitable donor.

The selected potential donors were subdivided into two groups:

Probable Donors. - These were patients whose clinical records indicated that they had healthy kidneys at the time of death and that the circumstances of death were such that kidney donations would have been practicable.

Possible Donors.-These were patients whose clinical records contained no evidence that kidney donation after death would have been contraindicated or impracticable, but which lacked enough information on which to make a more positive decision.

\section{Results}

More than 300 patients were excluded as potential kidney donors because their records contained evidence of coexistent diseases which had not been coded for H.A.A. The numbers of probable and possible kidney donors finally selected were 76 and 167 respectively (Table I). The total number of deaths in these hospitals during 1969 was approximately 7,700. Thus

TABLE I-Potential Kidney Donors: Hospital Survey 1969

\begin{tabular}{|c|c|c|c|c|}
\hline \multirow{2}{*}{\multicolumn{2}{|c|}{ Hospital }} & \multirow{2}{*}{$\begin{array}{l}\text { Hospital Deaths: } \\
\text { Age 15-55 years }\end{array}$} & \multicolumn{2}{|c|}{ Potential Kidney Donors } \\
\hline & & & Probable & Possible \\
\hline $\begin{array}{l}\text { Cardiff Royal Infirmary* } \\
\text { Morriston Hospital } \\
\text { Other general hospitals ... }\end{array}$ & $\ddot{0}$ & $\begin{array}{r}159 \\
28 \\
751\end{array}$ & $\begin{array}{l}29 \\
12 \\
35\end{array}$ & $\begin{array}{r}20 \\
10 \\
137\end{array}$ \\
\hline Total survey & .. & 938 & 76 & 167 \\
\hline
\end{tabular}

- Cardiff Royal Infirmary and Morriston Hospital have neurosurgical units. At Morriston Hospital, only the deaths in the neurosurgical unit were studied.

about $1 \%$ of all deaths were in the probable donor group. The number of discharges and deaths for these 27 hospitals in the same year was nearly 180,000 , which accounts for $84 \%$ of the discharges and deaths for "acute" hospitals in Wales and $57 \%$ of the total number of discharges and deaths for all hospitals in Wales. Fifty-four per cent. of probable donors and $18 \%$ of possible donors were patients who died in the two hospitals in the Welsh region which have neurosurgical units.

Table II shows the causes of death in the two groups of donors, and Table III shows the distribution according to age and sex. The predominant causes of death in the probable donor group were subarachnoid haemorrhage, head injury, and primary brain tumour, and the male to female sex ratio was $2 \cdot 2: 1$. The possible donor group includes 87 patients who 
TABLE II-Causes of Death of Potential Kidney Donors

\begin{tabular}{|c|c|c|c|}
\hline Cause of Death & & Probable Donors & Possible Donors \\
\hline $\begin{array}{l}\text { Subarachnoid haemorrhage } \\
\text { Head injury } \\
\text { Primary brain tumour } \\
\text { Self-poisoning } \\
\text { Coronary artery disease } \\
\text { Miscellaneous causes }\end{array}$ & $\begin{array}{l}\ddot{ } \\
\ddot{*} \\
\ddot{0}\end{array}$ & $\begin{array}{r}30 \\
22 \\
17 \\
3 \\
1 \\
3\end{array}$ & $\begin{array}{r}32 \\
12 \\
4 \\
16 \\
87 \\
16\end{array}$ \\
\hline All causes .. $\quad .$. & .. & 76 & 167 \\
\hline
\end{tabular}

TABLE II-Age and Sex Distribution of Potential Kidney Donors

\begin{tabular}{|c|c|c|c|c|c|c|c|}
\hline \multirow{2}{*}{\multicolumn{4}{|c|}{ Age in Years }} & \multicolumn{2}{|c|}{ Probable Donors } & \multicolumn{2}{|c|}{ Possible Donors } \\
\hline & & & & \multirow{2}{*}{$\begin{array}{c}\text { Male } \\
9 \\
7 \\
11 \\
25\end{array}$} & \multirow{2}{*}{$\begin{array}{c}\text { Female } \\
6 \\
2 \\
6 \\
10\end{array}$} & \multirow{2}{*}{$\begin{array}{c}\text { Male } \\
5 \\
6 \\
24 \\
85\end{array}$} & \multirow{2}{*}{$\begin{array}{c}\text { Female } \\
4 \\
4 \\
11 \\
28\end{array}$} \\
\hline $\begin{array}{l}15-24 \\
25-34 \\
35-44 \\
45-55\end{array}$ & $\ddot{0}$ & $\begin{array}{l}\because \\
\therefore\end{array}$ & $\begin{array}{l}\because \\
\cdots\end{array}$ & & & & \\
\hline$\overline{15-55}$ & $\ldots$ & .. & $\ldots$ & 52 & 24 & 120 & 47 \\
\hline
\end{tabular}

Probable donors: male to female sex ratio 2-2:1. Possible donors: male to female sex ratio $2 \cdot 6: 1$.

had died from myocardial infarction, and in this group the male to female sex ratio was $2 \cdot 6: 1$.

About half the potential donors were found to have had necropsies, and in no instance would the recorded findings have contraindicated kidney donation.

\section{Discussion}

The donor selection criteria used in this survey are similar to those described by Calne (1967), and are the same as those which we continue to use in practice, except that the age limits were more sharply defined. This age restriction may seem too stringent, since cadaveric kidneys taken from donors aged more than 70 years have been successfully transplanted on a number of occasions (Ende and Zukoski, 1965). Friedberg et al. (1970), reporting a similar survey of patients aged 11 to 70 years who died in the Kommunes Hospital, Copenhagen, in 1968, selected 45 potential kidney donors from 1,185 deaths, twothirds of whom were aged 61 to 70 years. Their selection was based on necropsy findings and kidney microscopy, which showed that only one potential donor had "more than slight" physiological ageing of his kidneys. There seems little doubt, therefore, that the potential supply of cadaveric kidneys would be greatly increased by considering deaths in this wider age range.

The 76 probable donors would theoretically provide 152 donor kidneys, but in practice this number would be reduced because the consent of surviving relatives cannot always be obtained. In our experience this has occurred in about $20 \%$ of cases. Also it is sometimes necessary to discard a particular donor kidney because of abnormalities discovered during its removal. Nevertheless, it seems likely that more than 100 cadaveric donor kidneys were potentially available from the probable donor group. This estimate may be increased by the inclusion of a certain number of kidneys from the possible donors. However, of the 167 of these it is likely that a considerable number would have been excluded if more complete clinical information had been available.
The number of potential kidney donors found by this survey may be compared with the number of deaths in the corresponding classifications recorded by the Registrar General. Terblanche and Riddell (1967) used data from the Registrar General's Statistical Review for 1964 to assess the availability of cadaveric donors for liver transplantation. Their "ideal donor group" comprised 3,613 deaths in England and Wales from subarachnoid haemorrhage, head injuries, and primary brain tumours in patients aged under 45 years. A similar analysis of the Registrar General's data for 1968 indicates about 250 deaths in Wales from the same causes in patients aged 15 to 55 years. In the present survey, only 117 such cases were discovered (Table II). We attribute the main reason for this difference to our exclusion of patients whose deaths occurred in circumstances which would make it difficult to undertake prompt postmortem removal of donor kidneys. Consequently, we have excluded those deaths which occurred within one hour of admission to hospital, since we have usually found this time to be insufficient to obtain adequate information about a patient and remove donor kidneys before they have been seriously damaged by ischaemia.

An important consideration is the extent to which supply matches demand. A recent survey in South Wales by Branch et al. (1971) indicated that the incidence of new patients under 50 years of age who were suitable for treatment by maintenance haemodialysis or kidney transplantation was probably between 25 and 30 per million per year. If this finding is applicable to Wales as a whole, with a population of 2.7 million, the number of new patients needing treatment each year will be somewhere between 68 and 81 . A proportion of these will be best treated by home dialysis, and it therefore seems that our estimated potential supply of more than 100 cadaveric kidneys per year should be adequate to meet the demand, at least during the next few years. It is, however, relevant to note that during 1969 only 17 of the probable donors identified in the survey became available to the Cardiff Kidney Transplant Unit.

From this study it seems that the persistent shortage of cadaveric donor kidneys is mainly the result of inadequate communication between the clinicians caring for potential donors and the surgeons working in kidney transplant units.

We thank the medical records staffs of the hospitals concerned in this survey for their helpful co-operation, and Dr. P. Alwyn Smith and members of the Welsh Hospital Board for permission to use the data and facilities of the Welsh Hospital Board's Computer Centre.

Requests for reprints should be sent to Mr. D. L. Crosby, Department of General Surgery, Cardiff Royal Infirmary, Newport Road, Cardiff CF2 1SZ.

\section{References}

Branch, R. A., Clarke, G. W., Cochrane, A. L., Jones, J. H., and Scarborough, H. (1971). British Medical fournal, 1, 249.

British Medical fournal, 1971a, 1, 301.

British Medical fournal, 1971b, 1, 688.

Calne, R. Y. (1967). Renal Transplantation, p. 153. London, Arnold

Ende, N., and Zukoski, C. F. (1965). Fournal of the American Medical Association, 191, 902.

Friedberg, M., Larsen, N. A., and Larsen, S. (1970). Proceedings of the European Dialysis and Transplant Association, 7, 295.

Terblanche, J., and Riddell, A. G. (1967). The Liver, ed. A. E. Read, p. 321. London, Butterworths. 